\title{
GEOGRAPHICAL ANALYSIS OF SIZE AND PATTERN OF VILLAGES IN RAMPUR DISTRICT
}

\section{जनपद रामपुर में ग्रामों का आकार एवं प्रतिरूप का भौगोलिक विश्लेषण}

\author{
Dr. L.B. Rawal ${ }^{1} \bowtie$, Saudan Singh ${ }^{2}$ \\ ${ }^{1}$ Former Principal, R.S.M. (P.G.), Kalij Dhampur (Bijnor), India \\ 2 M.A. (Geography), Net JRF, India
}

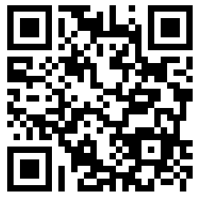

DOI: https://doi.org/10.29121/granthaalayah.v8.i7.2020.577

Article Type: Research Article

Article Citation: Dr. L.B. Rawal, and Saudan Singh. (2020).

GEOGRAPHICAL ANALYSIS OF SIZE

AND PATTERN OF VILLAGES IN

RAMPUR DISTRICT. International

Journal of Research -

GRANTHAALAYAH, 8(7), 46-49.

https://doi.org/10.29121/granthaa

layah.v8.i7.2020.577

Received Date: 25 June 2020

Accepted Date: 24 July 2020

Keywords:

अधिवास भूगोल

मानव भूगोल

ग्रामीण

\section{ABSTRACT}

English: Habitat geography is the new sprout branch of human geography. Both rural domicile and urban domicile are the two main strands of geography. Habitat geography studies the effect of physical and cultural considerations on man-made habitats, just as human geography describes the environment and human interactions. Human occupancy is the focal center within and around which man builds his culture. Human occupancy refers to all the natural elements and man-made structures that the process of habitat establishes, habitat boundaries that separate them from each other, spatial relationships that link them to both adjacent and remote areas, and The institute, which has been set up to maintain its social and cultural, economic, political and other importance.

Hindi: अधिवास भूगोल मानव भूगोल की नवीन अंकुरित शाखा है। ग्रामीण अधिवास और नगरीय अधिवास दोनों ही अधिवास भूगोल के दो प्रमुख तन्तु है। अधिवास भूगोल मानव द्वारा निर्मित आवासों पर भौतिक तथा सांस्कृतिक बातों के प्रभाव का अध्ययन करता है, ठीक उसी भाँति जिस प्रकार मानव भूगोल वातावरण तथा मानव के पारस्परिक सम्बन्धों का विष्लेशण करता है। मानव अधिवास वह नाभीय केन्द्र है जिनके भीतर व जिसके चारों ओर मानव अपनी संस्कृति का निर्माण करता है। मानव अधिवास उन सभी प्राकृतिक तत्वों और मानव निर्मित संरचनाओं की ओर संकेत करता है जो बसाव स्थापन की प्रक्रिया आवासों का स्थापन, मानवीय सीमाएँ जो उनको एक-दूसरे से अलग करती है, स्थानिक सम्बन्ध जो उसको समीपवर्ती तथा दूरस्थ दोनों ही क्षेत्रों से जोड़ते है तथा वह संस्थान सामाजिक सांस्कृतिक, आर्थिक, राजनीतिक तथा अन्य जिनका स्थापन उसे संचालित व प्रधानता बनाये रखने के लिए किया गया है।

\section{1. प्रस्तावना}

ग्रामीण अधिवास भूगोल के अध्ययन का प्रारम्भ रीटर के अध्ययनों द्वारा 19 वीं शताब्दी में हुआ है। वर्तमान (20 वीं) शताब्दी के प्रारम्भ से अनेक भूगोलवेत्ताओं ने अधिवास भूगोल का अध्ययन दो वर्गो के अन्तर्गत किए है। 1. इसके अन्तर्गत अधिवासों की वास्तविक स्थिति का अध्ययन, 2. इसके अन्तर्गत अधिवास-प्रक्रिया तथा भौगोलिक अभिव्यक्तियों का विवेचन सम्मिलित है। "अधिवास भूगोल की गृहों, जिसके द्वारा मानव स्वयं को प्राथमिक उत्पादन हेतु भूमि से जोड़ता है, के वितरण के वर्णन एवं विष्लेशण का अध्ययन कहा जा सकता है।" किन्तु उसने कुछ महत्वपूर्ण संघटकों जैसे गृह निर्माण पदार्थ, वास्तुकला एवं शिल्प, भूमि उपयोग तथा रक्षा सम्बन्धी अन्य निर्माण सम्मिलित नहीं किया है। 


\section{जनपद रामपुर में ग्रामों का आकार एवं प्रतिरूप का भौगोलिक विश्लेषण}

\section{2. अध्ययन क्षेत्र}

प्रस्तुत शोध-पत्र का अध्ययन क्षेत्र जनपद रामपुर है जो गंगा-रामगंगा के क्षेत्र का एक अभित्र अंग है। इसका अंक्षाशीय विस्तार 280ए 25ष् उत्तरी

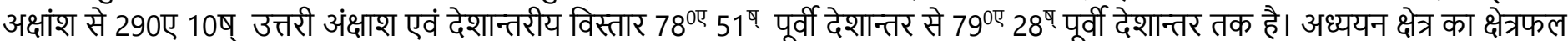
2367 वर्ग किलोमीटर है। जनपद रामपुर की उत्तरी सीमा जनपद ऊधम सिंह नगर (उत्तराखण्ड) एवं दक्षिणी सीमा पर बदायूँ जनपद का विस्तार है। इसके पूर्व में जनपद बरेली एवं पष्चिम में मुरादाबाद जनपद स्थित है।

प्रशासनिक दश्टि से जनपद रामपुर में 01 जनपद मुख्यालय (रामपुर), 06 तहसील मुख्यालय, 07 विकासखण्ड मुख्यालय 75 न्यायपंचायत, 580 ग्राम पंचायत एवं 1153 कुल राजस्व ग्राम सम्मिलित है। स्थानीय निकाय एवं प्रशासन की दृश्टि से 05 नगर पालिका परिशद एवं 03 नगर पंचायत स्थित है। वर्श 2011 की जनगणना के अनुसार कुल जनसंख्या 23.35 लाख व्यक्ति है एवं जनघनत्व 987 व्यक्ति प्रति वर्ग किलोमीटर है।

\section{3. प्राकृतिक दशायें}

जनपद रामपुर गंगा की ऊपरी घाटी में स्थित एक लघु भू-भाग है। जिसका निर्माण जहां पर प्रवाहित नदियों के जलोढ़ से हुआ है। इस क्षेत्र का ढाल उत्तर-पष्चिम से दक्षिण-पूर्व को है। इसकी औसत ऊँचाई $175-180$ मीटर है। रामगंगा एवं कोसी यहां की मुख्य नदिया है। स्वार एवं शाहबाद तहसीलों में वर्शा ऋतु में बाढ़ का प्रकोप बना रहता है। यहाँें पर परतदार अवसादी चट्टानों का विस्तार है जिनकी गहराई 1000-1500 मीटर है। यहां की जलवायु उश्णतर मानसूनी है। यहां का वार्शिक औसत तापमान 25.00 डिग्री सेल्सियस, वार्शिक वर्शा का औसत 115 सेन्टीमीटर, सापेक्षिक आर्द्रता 65-70 प्रतिशत एवं वायु की औसत गति 4.50-5.00 किलोमीटर है। मानसूनी पतझड़ी प्राकृतिक वनस्पति, वनों के अन्तर्गत क्षेत्रफल 6611 हेक्टेयर सामाजिक व कृशि वानिकी में सड़कों नहरों, मेढ़ों पर वृक्षारोपण अन्य प्रमुख विशेशतायें है। उपजाऊ जलोढ़ मिट्टी की उपलब्धता के कारण यह क्षेत्र कृषि प्रधान के अन्तर्गत है। उत्तरी दक्षिणी भागों में चिकनी, मध्य भागों में जलोढ़ एवं दोमट एवं दक्षिणी क्षेत्र में कटेहर उदला व भूड़ मिट्ली की उपलब्धता है।

\section{4. आर्थिक दशायें}

जनपद रामपुर आर्थिक दृश्टि से विकासशील अवस्था में है। वर्तमान में यहां की मुख्य आर्थिक क्रिया कृषि एवं पशुपालन है क्योंकि कुल कार्यशील जनसंख्या का 55 प्रतिशत भाग कृषि व पशुपालन क्षेत्र में संलग्र है। सकल प्रतिवेदित क्षेत्र के लगभग 80 प्रतिशत भाग पर कृषि कार्य किया जाता है। इसके साथ ही दो फसली क्षेत्र 65 प्रतिशत तथा कृशि गहनता 170 प्रतिशत कृषि क्षेत्र की उत्तम स्थिति का द्योतक है। औद्योगिक दृशि से चीनी विनिर्माण, मेन्थाघास से आॅयल आसवन व बोल्ड वनस्पति घी, हथकरघा उद्योग जैसे कुटीर व वृहद उद्योगों की इकाईयां स्थित है, जो मुख्यतः कृषि क्षेत्र पर ही निर्भर है। स्वार, बिलासपुर, शाहबाद, मिलक एवं रामपुर मुख्य औद्योगिक व व्यापारिक केन्द्र है। हावड़ा-अमृतसर, रामपुर-काठगोदाम दो मुख्य रेलमार्ग, दिल्ली-लखनऊ राश्ट्रीय राजमार्ग-24 रामपुर-नैनीताल प्रादेशिक राजमार्ग मुरादाबाद हवाई पट्टी इस क्षेत्र की परिवहन व्यवस्था के परिचायक है।

\section{5. ग्रामीण अधिवासों का स्वरूप}

जनपद रामपुर में कुल ग्रामों की संख्या 1163 है, जिसमें 1108 आबाद ग्राम एवं 55 ग्राम गैर-आबाद है। सघन ग्राम 30 प्रतिशत, संयुक्त ग्राम 20 प्रतिशत, अपखण्डित ग्राम 35 प्रतिशत एवं एकाकी ग्राम 15 प्रतिशत है। आकारानुसार ग्रामीण अधिवासों की गणना करने से स्पष्ट है कि 200 व्यक्ति से कम आकार वाले ग्रामों की संख्या 78, 200 से 499 व्यक्ति आकार वाले ग्राम 141, 500 से 999 व्यक्ति आकार वाले ग्राम 273, 1000 से 1499 व्यक्ति आकार वाले ग्राम 195, 1500 से 1999 व्यक्ति आकार वाले ग्राम 148, 2000 से 4999 व्यक्ति आकार वाले ग्राम 233 एवं 5000 से अधिक आकार वाले ग्रामों की संख्या 40 है। जैसा कि तालिका- से प्रदर्शित किया गया है।

तालिका संख्या 01: जनपद रामपुर में आकारानुसार ग्रामीण अधिवासों का वितरण, 2018

\begin{tabular}{|c|c|c|c|c|c|c|c|c|c|}
\hline $\begin{array}{l}\text { क्र० } \\
\text { सं० }\end{array}$ & विकासखण्ड & $\begin{array}{c}200 \text { व्यक्ति से } \\
\text { कम }\end{array}$ & $\begin{array}{c}200- \\
499\end{array}$ & $\begin{array}{c}500- \\
999\end{array}$ & $1000-1499$ & $1500-1999$ & $2000-4999$ & $\begin{array}{c}5000 \text { व्यक्ति से } \\
\text { अधिक }\end{array}$ & योग \\
\hline $1-$ & स्वार & 30 & 36 & 60 & 42 & 21 & 59 & 15 & 263 \\
\hline $2-$ & बिलासपुर & 37 & 47 & 55 & 35 & 24 & 23 & 4 & 225 \\
\hline $3-$ & सैदनगर & 2 & 11 & 19 & 23 & 20 & 29 & 7 & 111 \\
\hline $4-$ & चमरौआ & 1 & 10 & 30 & 24 & 23 & 30 & 5 & 123 \\
\hline $5-$ & शाहबाद & 6 & 22 & 48 & 35 & 28 & 44 & 6 & 189 \\
\hline $6-$ & मिलक & 2 & 15 & 61 & 36 & 32 & 48 & 3 & 197 \\
\hline \multicolumn{2}{|c|}{ योग जनपद } & 78 & 141 & 273 & 195 & 148 & 233 & 40 & 1108 \\
\hline
\end{tabular}




\begin{tabular}{|c|c|c|c|c|c|c|c|c|}
\hline प्रतिशत & 7.04 & 12.72 & 24.64 & 17.60 & 13.36 & 21.03 & 3.61 & 100. \\
\hline
\end{tabular}

स्रोतः जिला सांख्यिकीय पत्रिका, अर्थ एवं संख्या प्रभाग जनपद रामपुर 2018।

\section{6. ग्रामीण अधिवासों की विशेषतायें}

जनपद रामपुर में ग्रामों का घनत्व 48.10 प्रति 100 वर्ग किलोमीटर है। ग्रामों का औसत घनत्व 2.08 प्रति वर्ग किलोमीटर हैं ग्रामों में औसत जनसंख्या आकार 1577 व्यक्ति है। इसके साथ ही आवासीय घनत्व 125 प्रति वर्ग किलोमीटर है। जैसा कि तालिका- से स्पष्ट है।

तालिका संख्या 02: जनपद रामपुर में ग्रामीण अधिवासों की विशेशतायें, 2018

\begin{tabular}{|c|c|c|c|c|c|}
\hline $\begin{array}{r}\text { क्र0 } \\
\text { सं0 }\end{array}$ & विकासखण्ड & $\begin{array}{c}\text { गॉवों का घनत्व / } 100 \text { वर्ग } \\
\text { किलोमीटर }\end{array}$ & $\begin{array}{c}\text { गॉवो का औसत क्षेत्रफल वर्ग } \\
\text { किलोमीटर में }\end{array}$ & $\begin{array}{c}\text { गॉवों की औसत } \\
\text { जन संख्या }\end{array}$ & $\begin{array}{c}\text { आवासीय घनत्व प्रति वर्ग } \\
\text { किलोमीटर में }\end{array}$ \\
\hline $1-$ & स्वार & 47.67 & 2.10 & 1657 & 119 \\
$2-$ & बिलासपुर & 42.20 & 2.36 & 1057 & 124 \\
$3-$ & सैदनगर & 23.31 & 1.87 & 2057 & 122 \\
$4-$ & चमरौआ & 56.18 & 1.78 & 1807 & 130 \\
$5-$ & शाहबाद & 46.68 & 2.13 & 1676 & 123 \\
$6-$ & मिलक & 50.70 & 1.97 & 1454 & 125 \\
\hline \multicolumn{2}{r|}{ योग ग्रामीण } & 48.10 & 2.08 & 1577 & 127 \\
\hline
\end{tabular}

स्रोतः जिला सांख्यिकीय पत्रिका, अर्थ एवं संख्या प्रभाग जनपद रामपुर 2018 ।

जनपद रामपुर में गृह के प्रकार में एक कक्ष 14 प्रतिशत, जनसंख्या 8.50 प्रतिशत, दो कक्ष 20.00 प्रतिशत, जनसंख्या 15.50 प्रतिशत, तीन कक्ष 16.50 प्रतिशत, जनसंख्या 15.50 प्रतिशत, चार कक्ष 15.00 प्रतिशत, जनसंख्या 15.00 प्रतिशत, पा० च कक्ष 16.50 , जनसंख्या 25.00 प्रतिशत, छः कक्ष 8.00 प्रतिशत जनसंख्या 8.50 प्रतिशत, सात कक्ष 4.50 प्रतिशत, जनसंख्या 4.50 प्रतिशत, आठ कक्ष 1.50 प्रतिशत, जनसंख्या 1.00 प्रतिशत, नौ कक्ष 2.500 प्रतिशत, जनसंख्या 3.00 प्रतिशत एवं दस कक्ष 1.50 प्रतिशत, जनसंख्या 1.50 प्रतिशत है।

\section{7. निष्कर्ष एवं सुझाव}

जनपद रामपुर संस्थितियों में यथा-सम्भव सड़क, बिजली, मलनाली एवं पेयजल आदि सुविधाओं का विस्तार कर सुधार करने का प्रयास किया गया है। इसी प्रकार नहर के किनारे के ग्रामों में बाजार, ग्रामीण बैंक, सहकारी बैंक, प्राथमिक स्वास्थ्य केन्द्र, पंचायत घर, युवक मंगल केन्द्र, अन्र भण्डार, कृशि मशीनों के विक्रय एवं सुधारक केन्द्र, विद्यालय आदि सुविधाओं के अवस्थापना का सुझाव दिया गया है। शाहबाद-रामपुर सड़क के दोनों किनारों पर औद्योगिक आस्थान, शीतालय, प्राविधिक संस्थान, महा विद्यालय, डेयरी फार्म, डिस्पेन्सरी, वन बिहारी स्थल आदि के विकास का प्रस्ताव है जहां पवन और सौर ऊर्जा केन्द्रों की स्थापना पर बल दिया गया है। मलकुण्ड और मल साधन इकाई से पर्यावरण प्रदूशण के नियन्त्रण में मदद मिलेगी। जबकि रेशम कीट उत्पादन, मत्स्य पालन और डेयरी फार्मो से क्षेत्र के सुन्दरीकरण के साथ-साथ कृषकों के लिए अतिरिक्त आय का अवसर प्राप्त हो सकेगा। ग्राम वासियों को व्याख्यानों, जनसभाओं, जनसंचार माध्यमों आदि के माध्यम से स्वास्थ्य के प्रति जागरूक बनाना आवष्यक है।

\section{SOURCES OF FUNDING}

None.

\section{CONFLICT OF INTEREST}

None.

\section{ACKNOWLEDGMENT}

None. 


\section{जनपद रामपुर में ग्रामों का आकार एवं प्रतिरूप का भौगोलिक विश्लेषण}

\section{REFERENCES}

[1] तिवारी, आर0 सी0 1999 : अधिवास भूगोल प्रयाग पुस्तक भवन इलाहाबाद पृष्ठ-4

[2] ब्रून्हस जीन 1972 हामून ज्योग्राफी (ट्रान्सलेटेड वाई ई0 एफ0 रो) जार्ज जी हैरप एण्ड क० लि0

[3] ठाकुर बी० एस0 1990 अधिवास एवं जनसंख्या भूगोल किताब घर कानपुर पृष्ठ-10

[4] गैरीशन, डब्ल्यू० एल0 1973 फ्यूचर ज्योग्राफीज पृष्ठ-237

[5] डाक्सियाडिस सी० ए0 1968 एकिस्टिक्स, इन इन्ट्रोडक्शन टू दी साइन्स आॅफ हामून सेटिलमेन्टस न्यूयार्कः आक्सफोर्ड यूनिवर्सिटी प्रेस पृष्ठ-29-37

[6] स्मिथ डी० एम0 1974 हामून ज्योग्राफीः ए बेलफेयर एप्रोच एडवर्ड अरनाल्ड पृष्ठ-8

[7] सिंह, आर0 वाई0 2005 अधिवास भूगोल रावत पब्लिकेशन्स जयपुर पृष्ठ-8

[8] सिंह, के0 एन0 1977 इमरजेन्सी आॅफ मैन, कल्चर एण्ड सेटलमेन्ट इन इण्डिया पृष्ठ-4

[9] कोहन सी०एफ0 1954 : सेटलमेेन्ट ज्योग्राफी

[10] जिला विकास पुस्तिका सूचना एवं जनसम्पर्क विभाग जनपद रामपुर 2018। 